\title{
Risk factors for postpartum problems in dairy cows: Explanatory and predictive modeling
}

\author{
C. F. Vergara, ${ }^{*}$ D. Döpfer, ${ }^{*}$ N. B. Cook, ${ }^{*}$ K. V. Nordlund, ${ }^{*}$ J. A. A. McArt, † D. V. Nydam, † and G. R. Oetzel ${ }^{* 1}$ \\ *School of Veterinary Medicine, University of Wisconsin, Madison 53706 \\ †Department of Population Medicine and Diagnostic Sciences, College of Veterinary Medicine, Cornell University, Ithaca, NY 14853
}

\begin{abstract}
The postpartum period is associated with a high incidence of most dairy cattle diseases and a high risk of removal from the herd. Postpartum diseases often share risk factors, and these factors may trigger a cascade of other diseases. The objective of this cohort study was to derive explanatory and predictive models for treatment or removal from the herd within the first 30 $\mathrm{d}$ in milk (TXR30). The TXR30 outcome was specifically defined as $\geq 1$ treatment for $\geq 1$ occurrence of milk fever, retained placenta, metritis, ketosis, displaced abomasum, lameness, or pneumonia; removal from the herd (sold or died); or both treatment and later herd removal. The study population consisted of 765 multiparous and 544 primiparous cows (predominantly Holstein) from 4 large commercial freestall-housed dairy herds. Treatment or removal from the herd was recorded as a binary outcome for each cow. Potential explanatory and predictive variables were limited to routine cow data that could be collected either before or within $24 \mathrm{~h}$ of calving. Models for multiparous and primiparous cows were developed separately because previous lactation variables are available only for multiparous cows. Adjusted odds ratios for TXR30 in the explanatory model for the multiparous cohort were 2.1 for lactation 3 compared with lactation 2 , and 2.3 for lactation 4 or greater compared with lactation $2 ; 2.3$ for locomotion score 3 or 4 compared with score $1 ; 3.3$ for an abnormality at calving compared with no calving abnormality; 1.8 for each 1-standard deviation increase in previous lactation length; and 0.4 for each $5,000-\mathrm{kg}$ increment in previous lactation milk yield in cows with longer previous lactation length. The final predictive model for TXR30 in multiparous cows included predictors similar but not identical to those included in the explanatory model. The area under the curve for the receiver operating characteristic curve from the final predictive model for the multiparous cohort was 0.70 ,
\end{abstract}

Received November 30, 2012.

Accepted February 25, 2014.

${ }^{1}$ Corresponding author: groetzel@wisc.edu with $60 \%$ sensitivity. For the primiparous cohort, calving abnormality increased the odds of TXR30 and was the only variable included in both the explanatory and predictive models. The area under the curve for the receiver operating characteristic curve from the final predictive model for the primiparous cohort was 0.66 , with $35 \%$ sensitivity. This study identified key risk factors for TXR30 and developed equations for the prediction of TXR30. This information can help dairy producers better understand causes of postpartum problems.

Key words: transition period, explanatory modeling, predictive modeling, postpartum problems

\section{INTRODUCTION}

The 3- to 4-wk period before and after calving (the transition period) is crucial for a cow's health and longevity and for the profitability of the lactation. Calving is accompanied by the most significant endocrine changes at any point in time during the lactation cycle (Grummer et al., 2004). In addition, cows going through the transition period shift from positive energy balance to negative energy balance and experience substantial immune suppression (Burton et al., 2005; Hammon et al., 2006). Approximately $75 \%$ of disease in dairy cows occurs in the first 30 DIM (LeBlanc et al., 2006) and 30 to $50 \%$ of high-producing cows may be affected by some disease around calving (LeBlanc, 2010). The postpartum diseases of greatest interest are milk fever (MF), ketosis, displaced abomasum (DA), retained placenta (RP), uterine infections, and lameness. Incidences of these diseases and their relationship to changes that occur around calving have been described in detail (Ingvartsen et al., 2003; Nordlund and Cook, 2004).

Besides the occurrence of specific diseases, removal of a cow from the herd (due to either culling or death) during the postpartum period is another indication of difficulties during the transition period. Healthy cows are rarely culled in the postpartum period because they have the potential to produce milk for the remainder of the lactation. De Vries et al. (2010) reported that removals in early lactation were more likely to be due to death or injury compared with removals later in 
lactation. Dechow and Goodling (2008) concluded that herds with high early-lactation cull rates are likely to have poor transition cow health. Because cows may develop severe disease and either die or be removed from the herd before being fully diagnosed or treated, it is useful to include early-lactation removals in the evaluation of postpartum problems. More intensive monitoring or prophylactic treatment might prevent premature herd removal.

The greatest advances in dairy health in the last decades have been the shift to disease prevention, rather than treatment, as well as the shift from a focus on individual cows to groups of cows at risk. The recognition of the multifactorial nature of almost all diseases and the interconnected risk factors have been fundamental in understanding the biology of transition dairy cows (LeBlanc et al., 2006). For example, subclinical hypocalcemia can cause poor rumen motility, leading to reduced feed intake and increased risk of ketosis and displaced abomasum. Hypocalcemia can also cause dystocia due to poor uterine motility, which increases the risk of retained placenta and metritis (Guterbock, 2004). However, metritis or ketosis can occur without underlying hypocalcemia and can be primary conditions themselves that trigger a cascade of postpartum problems. These observations suggest that postpartum problems are appropriately evaluated as a combined outcome (i.e., the occurrence of any disease condition or herd removal during the postpartum period) and should not necessarily be restricted to evaluations of individual disease or herd removal outcomes. A limited number of studies have evaluated combined outcomes for postpartum problems (Ospina et al., 2010a; Huzzey et al., 2011). Combining postpartum disease occurrence and herd removal into a single outcome also has practical advantages, as it would enable dairy producers to better understand why certain cows require management attention after calving and others go through the postpartum period without problems.

Laboratory measurements have been used to predict cows that are at higher risk of certain diseases after calving or early culling. Elevated serum NEFA prepartum (LeBlanc, 2010; Ospina et al., 2010a; Chapinal et al., 2011), blood BHBA prepartum (LeBlanc et al., 2005; Chapinal et al., 2011; Roberts et al., 2012), serum Ca the week before and soon after calving (Chapinal et al., 2011; Seifi et al., 2011; Roberts et al., 2012), and fecal cortisol and haptoglobin (Huzzey et al., 2011) have been used to predict postpartum diseases. Of these tests, only BHBA can currently be conducted cowside. The other tests generally require submission of a sample to a laboratory, which is costly and delays receipt of the test result (LeBlanc, 2010). Thus, laboratory tests are limited in their practical value for identifying cows in the field that are at high risk of postpartum problems.

Several low-cost measures have been identified as potential predictors for postpartum health disturbances. Body condition score has been shown to be a useful monitor of energy balance during this period (Ingvartsen, 2006; Hoedemaker et al., 2009). Locomotion score has been widely used in epidemiological studies for prevalence of lameness calculations (Cook, 2003; Espejo and Endres, 2007), and lameness has been associated with increased risk of postpartum health problems and decreased survivability (Hoedemaker et al., 2009; Calderon and Cook, 2011; Machado et al., 2011). Lameness has also been associated with decreased feeding time (Gomez and Cook, 2010) and increased blood BHBA concentrations after calving (Calderon and Cook, 2011). In addition, other risk factors such as previous lactation milk yield, previous lactation length, dry period length, gestation length, twins, dystocia, and stillbirths may be important determinants of postpartum performance in dairy cows (Fleischer et al., 2001; Ingvartsen, 2006; LeBlanc et al., 2006); however, they have not been combined into predictive models.

Modeling of postpartum problems must necessarily be different for primiparous versus multiparous cows. Primiparous cows have no previous lactation data to consider; thus, they have fewer variables available for evaluation as risk factors for postpartum problems. Underlying biological differences between primiparous and multiparous cows might also exist due to parity in transition cows. Cheong et al. (2011) reported that early lactation milk yield had opposite effects on the odds for subclinical endometritis in primiparous versus multiparous cows (increasing milk yield increased the odds for subclinical endometritis in primiparous cows but lowered the odds for multiparous cows). Ospina et al. (2010b) reported that primiparous cows with elevated prepartum NEFA had increased milk yield in the subsequent lactation, but that multiparous cows with elevated prepartum NEFA had decreased milk yield.

Statistical modeling can involve 3 approaches (Shmueli, 2011). Explanatory modeling is oriented toward causal explanation of the outcome, predictive modeling emphasizes mathematical prediction of the outcome, and descriptive modeling represents the data in a compact manner. Explanatory modeling is done to test causal hypotheses and is the most common approach for evaluating biological outcomes. The purpose of explanatory modeling is to identify all possible risk factors (including as many interactions as feasible) and to then characterize the direction and magnitude of the effects. In contrast, the purpose of predictive modeling is the prediction of new or future observations; it em- 
phasizes maximizing predictive power. An advantage of predictive modeling is that prediction accuracy can be observed; in contrast, explanatory models can never be confirmed and are harder to contradict. Disadvantages of predictive modeling include controversy about the value of prediction in developing scientific theories and the general lack of familiarity with the statistical methods and outcomes generated by predictive modeling (Shmueli, 2011). The application of both modeling approaches to the evaluation of postpartum problems in dairy cattle should improve our understanding of these problems.

The first objective of this study was to use explanatory modeling to test the hypotheses that significant risk factors for postpartum problems (defined as a single binary outcome) could be identified from data that are routinely available for cows before parturition and within $24 \mathrm{~h}$ after calving. The second study objective was to derive predictive models that would predict the probability of postpartum problems (also defined as a single binary outcome).

\section{MATERIALS AND METHODS}

\section{Study Population}

The study population came from 4 large commercial freestall-housed dairies with predominantly Holstein cows. Two herds were located in New York (herds A and $\mathrm{B}$ ) and 2 in Wisconsin (herds $\mathrm{C}$ and D). Data were collected during the summer of 2010 . Study herds met the following criteria: at least 1,500 milking cows; headlocks in the prepartum and postpartum cow pens; a postpartum pen monitoring routine; and use of Dairy Comp 305 (Valley Agricultural Software, Tulare, CA) for recording of health and culling events. A description of each herd's management and nutrition has been published previously (McArt et al., 2011). This study was part of 2 larger randomized field trials (McArt et al., 2011; Oetzel and Miller, 2012). Only cows assigned to the control groups of the randomized trials were included in the current study. The owners of the study herds signed an informed consent form. Protocols were reviewed and approved by the Cornell University Institutional Animal Care and Use Committee (\#20080099) and the University of Wisconsin-Madison School of Veterinary Medicine Animal Care and Use Committee (\#V01479-0-05-10).

\section{Data Collection}

Cows were evaluated for prepartum locomotion score and BCS once during the $3 \mathrm{wk}$ before expected calving. Scoring was conducted twice weekly in the New
York herds and once weekly in the Wisconsin herds. Sampling occurred $13.0 \mathrm{~d}$ ( $\mathrm{SD}=9.6 \mathrm{~d}$ ) before calving for multiparous cows and $11.5 \mathrm{~d}(\mathrm{SD}=8.1 \mathrm{~d})$ before calving for primiparous cows. Locomotion score was determined using the 1- to 4-point scoring system described by Nordlund et al. (2004). Scores were collapsed into 3 groups: nonlame (score 1), slightly lame (score 2), and moderately or severely lame (score 3 or 4). Prepartum BCS was assessed using a 1- to 5-point scoring system with 0.25-unit increments as described by Ferguson et al. (1994). Scores were collapsed into 3 groups: thin $(\leq 3.0)$, moderate (3.25 to 3.75$)$, and fat $(\geq 4.0)$. For the Wisconsin herds, one trained evaluator assigned all the prepartum locomotion score and another trained evaluator assigned all the prepartum BCS. All scores in the New York herds were assigned by a single evaluator.

Eighty-two cows in 1 herd were jointly scored for prepartum locomotion score and BCS by all 3 evaluators. Weighted kappa values, a measure of agreement beyond chance between raters (Landis and Koch, 1977), were determined. The weighted kappa value was 0.44 (moderate agreement) for locomotion score and 0.19 (slight agreement) for BCS. Because the kappa values were low, the scores were collapsed into categories as described above. This improved the weighted kappa values to 0.47 for locomotion score group and to 0.24 for BCS group.

Additional data came from each herd's computerized records. Explanatory variables used for both the multiparous and primiparous cohorts included gestation length and calving information (twins, stillbirth, or dystocia). Dystocia was defined as calving difficulty score $\geq 3$ using a 1 - to 5 -point scale, in which 1 represented no calving assistance and 5 represented extreme assistance. Covariates applied only to multiparous cows were parity (collapsed into second, third, or fourth and greater lactation category), previous lactation matureequivalent milk yield $(\mathrm{kg} / 305 \mathrm{~d})$, previous lactation length, and dry period length. Age at calving was recorded for primiparous cows only.

A total of 2,587 cows gave birth during the study period, which lasted from May 18 until September 2, 2010; 1,624 calvings were from multiparous cows and 963 calvings were from primiparous cows. Animals removed from the analysis included cows randomly assigned to a treatment group (708 multiparous and 128 primiparous); cows with missing data for prepartum locomotion score or prepartum BCS or both (139 multiparous and 271 primiparous); cows with gestation length $<260 \mathrm{~d}$ or abortions (10 multiparous and 7 primiparous); or cows with incomplete data (2 multiparous and 13 primiparous). A total of 765 multiparous and 544 primiparous cows were included in the analysis. 


\section{Study Outcomes}

The outcome of interest was treatment $\geq 1$ time for $\geq 1$ disease of interest within $30 \mathrm{~d}$ of calving, removal from the herd (sold or died) within $30 \mathrm{~d}$ of calving, or both treatment and later removal from the herd within $30 \mathrm{~d}$ of calving (TXR30). The TXR30 outcome was recorded as a binary outcome for each cow enrolled in the study. Diseases of interest included MF, RP, metritis, ketosis, DA, lameness, and pneumonia. Each farm was given a written description of the criteria for diagnosing these diseases. Briefly, MF was defined as weakness, ataxia or recumbency within $48 \mathrm{~h}$ of calving, without clinical signs of toxemia, that was treated with intravenous or oral calcium; RP was defined as failure to pass fetal membranes within $24 \mathrm{~h}$ of calving; metritis was defined as abnormal vaginal discharge plus fever, decreased milk yield, or dull attitude within $21 \mathrm{~d}$ of calving that was treated with antibiotics; ketosis was defined as poor appetite, sudden weight loss, or decreased milk yield with no clinical signs of other disease, confirmed by a cowside ketone test (urine, milk, blood, or breath smell), and treated with oral propylene glycol or an IV solution containing dextrose; DA was defined as either left or right displacement of the abomasum that was diagnosed by auscultation of a characteristic ping; lameness was defined as observation of lameness that resulted in presenting the cow for hoof trimming and treatment; and pneumonia was defined as fever plus abnormal nasal discharge or respiratory effort that was treated with antibiotics.

The diseases of interest for this study were limited to those that are typically diagnosed and treated in either the postpartum or maternity pens. Mastitis events were not included in this study because the diagnosis and treatment of mastitis is typically done in the parlor and not by the individuals caring for the postpartum cows.

\section{Explanatory and Predictive Variables}

Potential explanatory and predictive variables for TXR30 were limited to data available from a cow's record before calving and up to $24 \mathrm{~h}$ after calving. This corresponds to the time period in which dairy producers would need to decide whether a cow should be moved to a special postpartum pen, be tested more intensively for postpartum disease, or receive specific prophylactic treatment(s).

Calving information was combined into a single dichotomous calving abnormality variable. A value of 1 for calving abnormality was assigned to cows with one or more of the following: birth of twin calves, birth of a dead calf, or dystocia (calving ease score $\geq 3$ using a scale of 1 to 5); otherwise, animals were assigned a value of 0 (normal calving). The first category in alphabetical or numerical order was used as the reference level for categorical covariates herd, parity, calving abnormality, and prepartum locomotion score. The middle category was used as the reference for prepartum BCS.

To make the model coefficients more homogeneous and comparable between variables, all continuous independent variables were centered at the median value for the sample population. As a result, the intercept and baseline of the logistic models represented the 50 th percentile. Continuous independent variables were standardized to some unit of interest, in most cases 1 standard deviation (SD); thus, 1 unit of change for any independent variable represented approximately the same amount of variation in the sample. For multiparous cows, previous lactation mature-equivalent milk production $(\mathrm{kg} / 305 \mathrm{~d})$ was centered to $14,700 \mathrm{~kg}$ and standardized by $5,000-\mathrm{kg}$ units of change; previous lactation length was centered to $328 \mathrm{~d}$ and standardized by $67 \mathrm{~d}(1 \mathrm{SD})$; dry period length was centered to $50 \mathrm{~d}$ and standardized by $16 \mathrm{~d}$ (1 SD); and gestation length was centered to $278 \mathrm{~d}$ and standardized by $5 \mathrm{~d}$ (1 SD). For primiparous cows, age at calving was centered to $701 \mathrm{~d}$ and standardized by $70 \mathrm{~d}$ (1 SD); gestation length was centered to $275 \mathrm{~d}$ and standardized by $6 \mathrm{~d}$ (1 SD).

\section{Statistical Analyses}

Descriptive Statistics. Descriptive statistics for the distribution of the TXR30 outcome, the specific reasons for postpartum disease treatment or number of removals by 30 DIM, and explanatory variables of the TXR30 outcome were generated using the MEANS and FREQ procedures of SAS (version 9.2; SAS Institute Inc., Cary, NC).

Explanatory Models. Multivariable logistic regression models were developed with the objective of understanding the biology underlying the TXR30 outcome. Models were constructed with a binomial distribution and a logit link using the GENMOD procedure of SAS. Cow was the observational unit. Multiparous and primiparous cohorts were modeled separately. Potential explanatory variables were tested for collinearity before modeling, using the CORR procedure of SAS. All correlations between variables were small $(\mathrm{r}<0.30)$. Herd (as a fixed effect) and all 2-way interactions between variables were offered to the models. Variables were removed by manual backward stepwise elimination until all terms (or their interactions) were $P<0.05$ in the model. Single variables included in one or more interaction(s) $(P<0.05)$ were always retained in the model. A backward elimination approach is most appropriate for finding important interactions (Vittinghoff et al., 2005). 
The odds ratio (OR) and its Wald 95\% CI were estimated for each explanatory variable or interaction term that remained in the model for each cohort. The OR represented the effect size of a 1-unit increment of change in the variable from its baseline value on the odds of TXR30. The baseline or intercept was equivalent to a cow with median values for the continuous covariates and in the lower (numerical or alphabetical) category of reference for categorical variables. The unit increment was then equivalent to the specific standardization of each continuous variable, or going from the reference level to the next category for categorical variables.

Predictive Models. Multivariable logistic regression models for the prediction of the probability of TXR30 were constructed using the GENMOD procedure of SAS, using a binomial distribution and logit link. Multiparous and primiparous cohorts were modeled separately. Cow was the observational unit. Predicted probabilities for TXR30 (by definition constrained to a range between 0 and 1) were calculated for each cow. Herd was considered a random effect (repeated subject), and the exchangeable correlation matrix structure was specified.

Predictive models were constructed in a manual forward stepwise fashion with the goal of maximizing predictive accuracy. The area under the curve (AUC) for the receiver operating characteristic (ROC) curve was used as the measure of predictive accuracy (Greiner et al., 2000). The addition of a new predictor was contrasted with the precedent model using the ROCCONTRAST statement of the LOGISTIC procedures of SAS (DeLong et al., 1988). A full set of 8 potential predictors for the multiparous cows (previous lactation mature-equivalent milk production, lactation group, prepartum locomotion score, prepartum BCS, calving abnormality composite, gestation length, dry period length, and previous lactation length) and 5 predictors for the primiparous cows (age at calving, gestation length, prepartum locomotion score, prepartum BCS, and calving abnormality composite) were offered for model construction. At each step, the single variable that resulted in the greatest increase in the AUC of the model was added to the model, as long as the increase in AUC was $P<0.20$ and if the variable was $P<0.05$ in the model. When no more single variables met the eligibility criteria for inclusion in the model, all possible 2-way interactions between the variables already in the model were assessed in a similar forward stepwise fashion. Interactions were retained in the model only if they increased the AUC $(P<0.20)$ compared with the model containing only the single predictors and if the interaction term was $P<0.05$. The forward addition of interactions stopped when the latest addition resulted in the lowest quasi-likelihood under the independence model criterion (QIC) statistics for the specific model size, and when the addition was confirmed by finding no improvement in sensitivity and specificity at a specific fixed cut point compared with further models that included additional interactions.

After the initial set of predictors and their interactions was determined, the predictive models were further developed by adding the next best single variable (based on the earlier evaluation using only individual variables) to the model. All possible 2-way interactions with this variable were also evaluated, using the same criteria described above. If the addition of this new variable or any of its interactions did not meet the criteria, then the variable (and its interactions) was discarded and the next best predictor for increasing AUC from the initial evaluation of individual variables was tested in a similar fashion. The final model consisted of the single variables and interaction terms that met all of the criteria.

The interpretation of the predictive ability of the AUC value was based on the description of Swets (1988), in which AUC $\leq 0.50$ was considered noninformative, AUC between 0.50 and 0.70 was considered accurate, AUC between 0.70 and 0.90 was considered very accurate, and AUC between 0.9 and 1.0 was considered highly accurate to perfect in terms of model prediction and fit.

The accuracy of the 2 equations derived from the predictive modeling (one for the multiparous cohort and one for the primiparous cohort) was evaluated by determining each equation's sensitivity and specificity. This required selecting a cut point (necessarily between 0.00 and 1.00) for each equation. Predicted probabilities above the cut point were considered positive predictions for TXR30, and those below the cutpoint were considered negative predictions. The cutpoint that resulted in the highest combined sensitivity and specificity for the prediction of actual TXR30 was selected for each equation. The accuracy of predictions based on these cut points was evaluated by calculating their sensitivity and specificity.

\section{RESULTS AND DISCUSSION}

\section{Multiparous Cows}

Descriptive Statistics. The incidence of TXR30 in multiparous cows was $38.2 \%$ (292 of 765 cows). Table 1 shows the distribution of TXR30 and the individual components of TXR30 (individual diseases and removals) by herd. The overall disease incidence rates and the variation between herds generally agreed with Ingvartsen et al. (2003), who reviewed 25 studies of production disease incidences. The exception was ketosis, which was higher in the current study; this was 
Table 1. Number (\% in parentheses) of multiparous cows affected by study outcomes from cows in 4 commercial dairies with predominantly Holstein cows

\begin{tabular}{lccccc}
\hline Variable & Herd A & Herd B & Herd C & Herd D & All herds \\
\hline No. of cows & 157 & 207 & 229 & 172 & 765 \\
TXR30 & $48(30.6)$ & $95(45.9)$ & $111(48.5)$ & $38(22.1)$ & $292(38.2)$ \\
Milk fever & $3(1.9)$ & $1(0.5)$ & $4(1.8)$ & $0(0.0)$ & $8(1.1)$ \\
Retained placenta & $30(19.1)$ & $28(13.5)$ & $26(11.4)$ & $10(5.8)$ & $94(12.3)$ \\
Metritis & $15(9.6)$ & $61(29.5)$ & $37(16.2)$ & $18(10.5)$ & $131(17.1)$ \\
Ketosis & $14(8.9)$ & $19(9.2)$ & $72(31.4)$ & $16(9.3)$ & $121(15.8)$ \\
Displaced abomasum & $4(2.6)$ & $10(4.8)$ & $11(4.8)$ & $4(2.3)$ & $29(3.8)$ \\
Lameness & $6(3.8)$ & $27(13.0)$ & $5(2.2)$ & $2(1.2)$ & $40(5.2)$ \\
Pneumonia & $0(0.0)$ & $0(0.0)$ & $13(5.7)$ & $2(1.2)$ & $15(2.0)$ \\
Removed & $5(3.2)$ & $8(3.9)$ & $20(8.7)$ & $9(5.2)$ & $42(5.5)$ \\
\hline
\end{tabular}

${ }^{1}$ Cows that, within $30 \mathrm{~d}$ of calving, received $\geq 1$ treatment for $\geq 1$ disease of interest, were removed from the herd, or both. Postpartum diseases of interest were milk fever, retained placenta, metritis, ketosis, displaced abomasum, lameness, and pneumonia.

exclusively due to herd C. Despite efforts to standardize disease definitions, differences in diagnostic abilities and protocols for recording disease information may explain the variation in incidences for diseases such as ketosis, pneumonia, and lameness (Nordlund and Cook, 2004). Combining postpartum cow problems into a single outcome may overcome some of these limitations.

The overall proportion of removals by 30 DIM was $5.5 \%$ and ranged from 3.2 to $8.7 \%$ for the 4 study herds. These rates are low compared with other herds and reflect excellent transition cow management. Other studies report removal rates by 60 DIM and suggest a goal of $<6 \%$ (Nordlund and Cook, 2004). However, most postpartum problems occur in the first 30 DIM. De Vries et al. (2010) evaluated records from $>2$ million lactations in 727 herds from the eastern United States; they reported that culling hazard first peaks by d 30 postpartum in multiparous cows.

Table 2 summarizes all potential explanatory variables for TXR30 in multiparous cows. Milk yield was relatively high for the study herds (mean of 14,684 kg of previous lactation mature-equivalent milk production in $305 \mathrm{~d}$ ). This equals approximately the 80th percentile for mature-equivalent milk production from large herds enrolled in Wisconsin DHI (AgSource, 2014). Average herd lactation length was $349 \mathrm{~d}$, which was very similar to the calculated average lactation length (calving interval - days dry) of $346 \mathrm{~d}$ for large herds from a national dairy survey (USDA, 2007). Average dry period length was $53 \mathrm{~d}$, which was slightly lower than but similar to the average dry period length of $60 \mathrm{~d}$ for large herds from the same national survey (USDA, 2007). The prevalence of prepartum lameness (locomotion score 3 or 4 ) averaged $11.2 \%$ (range of 8.7 to $13.4 \%$ ); these were very low prevalences of lameness compared with the average lameness prevalence of 38\% from 121 North American herds reported by von Keyserlingk et al. (2012). The proportion of overconditioned prepartum cows (BCS $\geq 4.00$ ) was likewise low, with an overall mean of $4.8 \%$, and was generally consistent between herds (range of 1.7 to $8.7 \%$ ). Two previous studies each reported $7 \%$ prevalences of postpartum BCS $\geq 4.00$ (Ruegg and Milton, 1995; Markusfeld et al., 1997). Rates of prepartum BCS $\geq 4.00$ would be expected to be higher than the postpartum rates, because BCS declined 0.25 units from prepartum to postpartum (Ruegg and Milton, 1995).

Explanatory Model. The final explanatory model for TXR30 in the multiparous cows is presented in Table 3. The odds of TXR30 were increased for cows in their third or greater lactation, cows that were lame before calving, cows that had an abnormality at calving, and cows with a longer previous lactation length. Cows with both a calving abnormality and longer previous lactation length had particularly high odds of TXR30. Higher previous lactation milk yield reduced the odds of TXR30 for cows with longer previous lactation length. Other variables included in the final explanatory model for multiparous cows were herd, interactions between herd and previous lactation length, interaction between calving abnormality and previous lactation length, and interaction between previous lactation mature-equivalent milk production and previous lactation length (Table 3).

Increasing parity has been commonly identified as a risk factor or co-factor for many postpartum diseases; this was confirmed in the current study. Third and fourth or greater parity cows had 2.1 (95\% CI: 1.4 to 3.2 ) and 2.3 (95\% CI: 1.5 to 3.5) times greater odds, respectively, for TXR30 compared with second-lactation cows. Increasing parity has been associated with higher risk of culling (De Vries et al., 2010) and with higher risk of postpartum diseases such as RP, DA, subclinical ketosis, and lameness (Machado et al., 2010; Huzzey et al., 2011).

A confounding effect between age and BCS could be responsible for the lack of significance of BCS in the current study. Machado et al. (2011) predicted lame- 
Table 2. Means ( \pm SEM; \% in parentheses for categorical variables) of continuous explanatory variables and the number and percentage of cows affected for categorical explanatory variables eligible to explain TXR30 ${ }^{1}$ in multiparous cows from 4 commercial dairies with predominantly Holstein cows

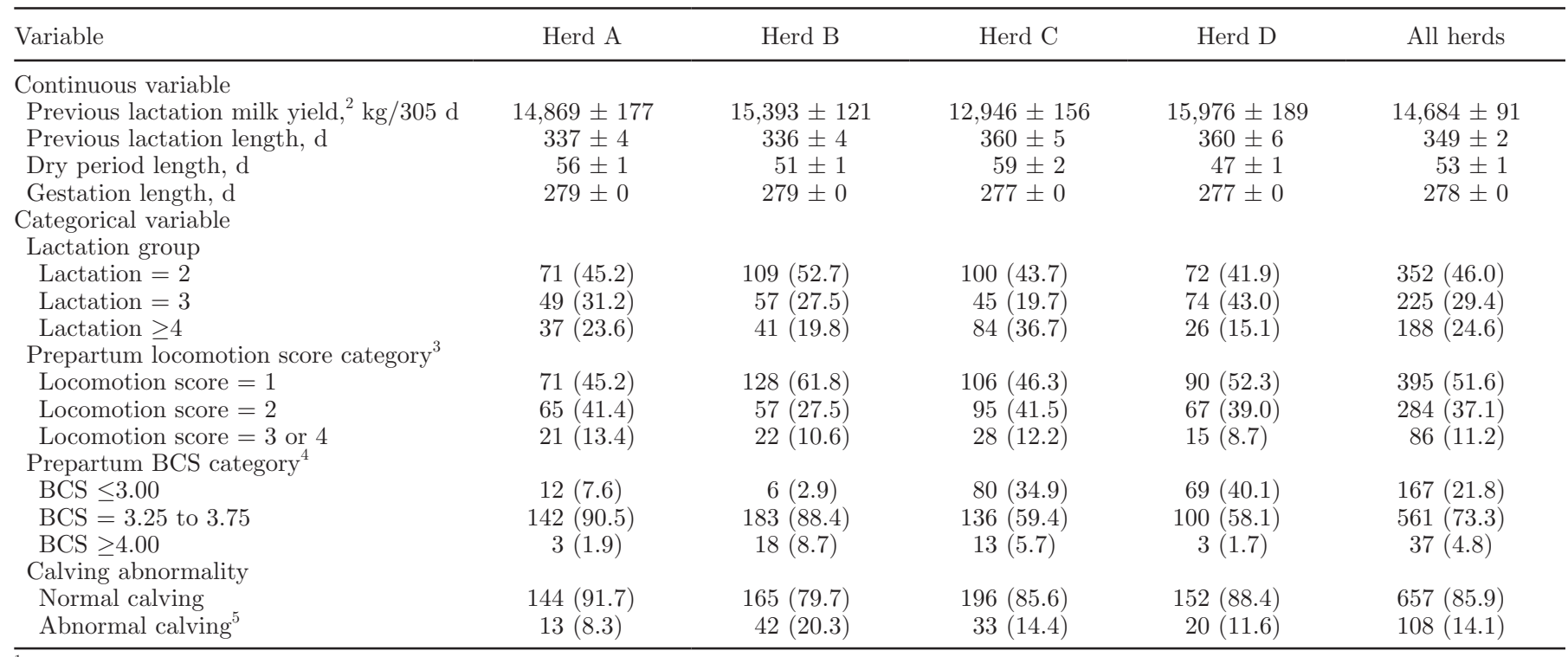

${ }^{1}$ Cows that, within $30 \mathrm{~d}$ of calving, received $\geq 1$ treatment for $\geq 1$ disease of interest, were removed from the herd, or both. Postpartum diseases of interest were milk fever, retained placenta, metritis, ketosis, displaced abomasum, lameness, and pneumonia.

${ }^{2}$ Mature-equivalent milk production (kg/305 d) in the previous lactation.

${ }^{3}$ Determined using a scale of 1 to 4 .

${ }^{4}$ Determined using a scale of 1 to 5 .

${ }^{5}$ One or more of the following: birth of twin calves, birth of a dead calf, or calving ease score $\geq 3$ using a scale of 1 to 5 .

ness in the subsequent lactation from data collected in the previous dry period and noted that older cows tended to be thinner and have a higher prevalence of lameness. They suggested that both low BCS and increasing parity could be explaining similar variation for the increasing risk of lameness at older age. In the current study, lameness was significant in the final models for the multiparous cohort but BCS was not. Other possible explanations for the lack of significance of BCS in the models could be the low weighted kappa values for BCS between observers or the relatively low number of cows with $\mathrm{BCS} \geq 4$.

Moderately to severely lame cows (prepartum locomotion score $=3$ or 4 ) had much higher odds of TXR30 than did nonlame cows (OR $=2.3 ; 95 \%$ CI: 1.3 to 4.0$)$. Only $11.2 \%$ of the prepartum cows scored in the currently study had locomotion score $=3$ or 4 . Machado et al. (2010) selected a herd with a high prevalence and reported $24 \%$ lameness in dry cows. Both studies agree that prepartum lameness is associated with increased odds of culling, although the current study differs by being unable to identify prepartum BCS as another risk factor.

Machado et al. (2010) found higher odds of culling in cows with a prepartum BCS of $<3.00$. However, the number of cows that were both thin and lame was much smaller in the current study (11 vs. $24 \%$ lameness and 7.3 vs. $19.7 \%$ of cows with prepartum BCS $\leq 2.75$ ).

Other studies have associated lameness in the dry period with increased risk of postpartum health problems and decreased survivability (Hoedemaker et al., 2009; Calderon and Cook, 2011; Machado et al., 2011). Lameness has been associated with reduced feeding time (Gomez and Cook, 2010) and increased blood BHBA concentrations after calving (Calderon and Cook, 2011). The results of the current and previous studies indicate that routine monitoring of prepartum locomotion score could be a very useful practice, both as a means of monitoring lameness and as an explanation for postpartum problems.

Calving abnormalities (twins, stillbirths, or dystocia) were combined into a single variable (calving abnormality), which was present in $14.1 \%$ of the multiparous cows. The incidence of dystocia (defined as a calving difficulty score $\geq 3$ ) was $7.2 \%$, the incidence of twin calvings was $6.8 \%$, and the incidence of stillborn calves (dead within $24 \mathrm{~h}$ postpartum) was $3.3 \%$ for the multiparous cows. Cows with a calving abnormality had 3.3 times greater odds (95\% CI: 2.0 to 5.4) of being treated or removed by 30 DIM compared with cows that calved without abnormality but with the same median previous lactation length $(328 \mathrm{~d})$. Other studies have found 
Table 3. Explanatory model ${ }^{1}$ for the odds of TXR $30^{2}$ for multiparous cows from 4 commercial dairies with predominantly Holstein cows

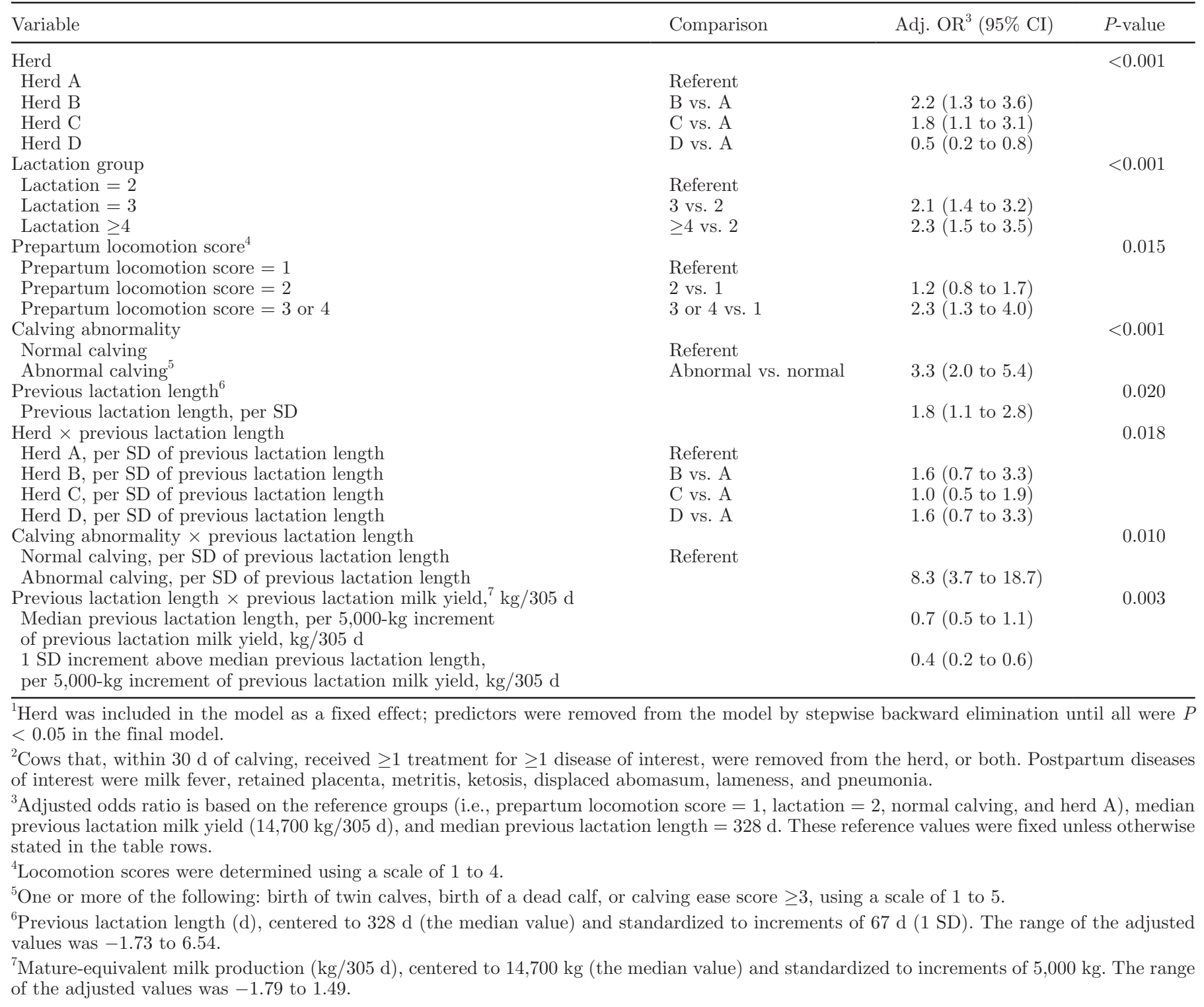

associations of calving abnormalities with disease incidence. Dystocia and twinning increased the odds of uterine disease and DA, and stillbirths increased the odds of culling (LeBlanc et al., 2005; Bicalho et al., 2008; Dubuc et al., 2010).

In the current study, cows with a longer previous lactation length $[67 \mathrm{~d}(1 \mathrm{SD})$ longer than the mean of $349 \mathrm{~d}$ ] together with a calving abnormality had 8.3 times greater odds of TXR30 (95\% CI: 3.7 to 18.7; Figure 1). We are not aware of any previous reports of an interaction between calving abnormality and previous lactation length for explaining the risk of postpartum problems. We are also not aware of an obvious biological mechanism to explain this interaction.
Increasing previous lactation mature-equivalent milk yield $(\mathrm{kg} / 305 \mathrm{~d})$ greatly reduced the odds of TXR30, although only for cows with longer previous lactation length. A 5,000-kg increase in previous lactation mature-equivalent milk, combined with increasing lactation length by $67 \mathrm{~d}$, resulted in much lower odds of TXR30 (OR $=0.4 ; 95 \%$ CI: 0.2 to 0.6 ).

Published reports on the association between previous lactation milk production and the odds of postpartum disease have been inconsistent or ambiguous (Ingvartsen et al., 2003). Fleischer et al. (2001) speculated that important interactions could exist between milk yield and other predictors of disease related to management issues. Our results indicated a protective 


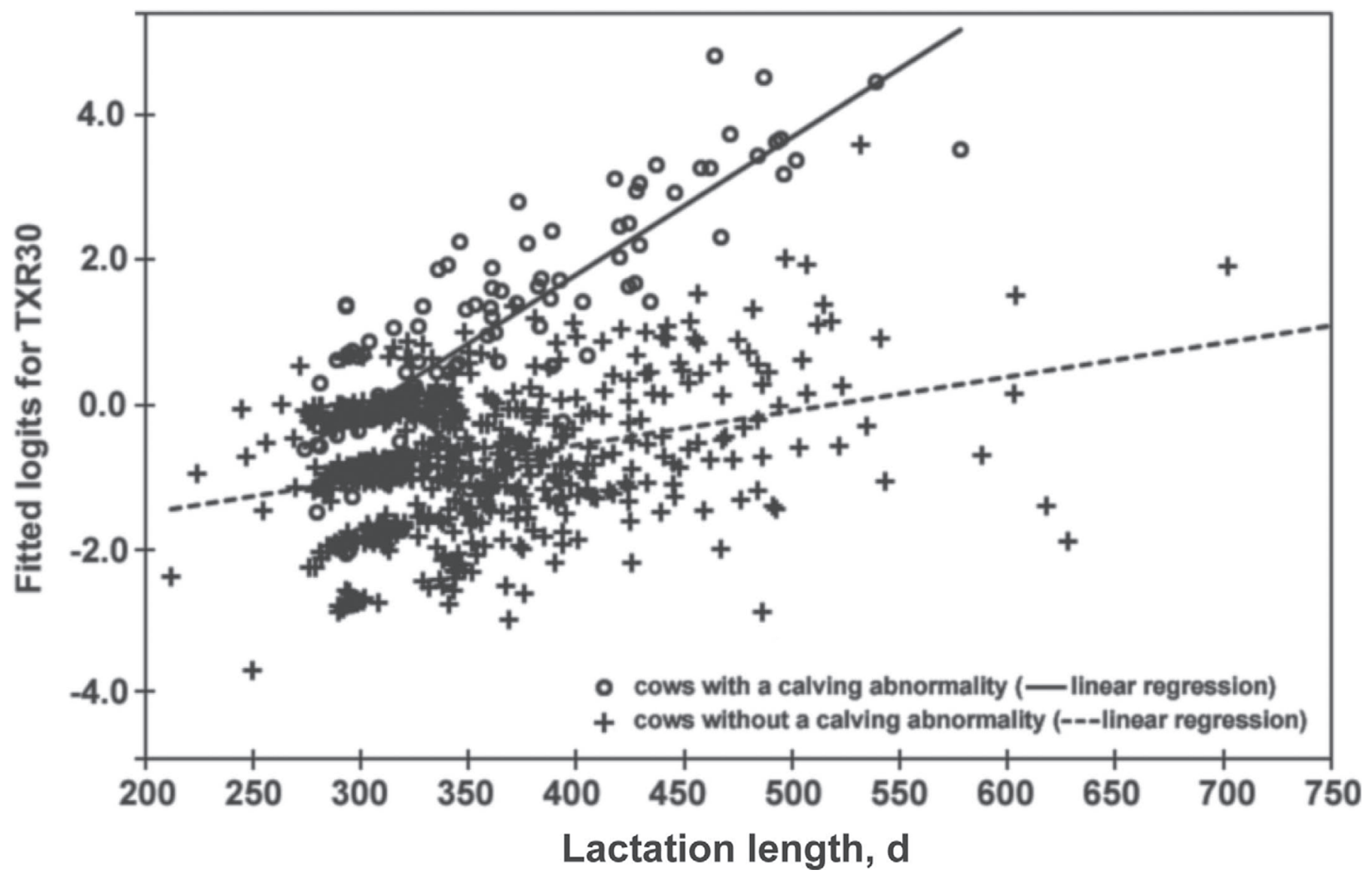

Figure 1. Graphical representation of the interaction between previous lactation length and calving abnormality for a model explaining postpartum disease treatment, herd removal, or both by 30 DIM (TXR30) for multiparous cows in 4 commercial Holstein herds. The interaction between previous lactation length and calving abnormality was included $(P=0.01)$ in the final logistic regression model. Results are plotted as the fitted logits from the final logistic regression model.

effect of higher previous lactation milk yield on TXR30 when previous lactation length was longer.

Herd was included as a fixed effect in the explanatory models to allow for the best possible explanation of the biology of TXR30. Herd remained in the final explanatory model $(P<0.001)$ for multiparous cows and interacted with previous lactation length $(P=0.02$, Table 3). This illustrates the strong influence of general herd management on the risk of postpartum problems. Herd was included as a random effect in the predictive modeling to correct for within herd clustering.

Predictive Model. The prediction equation for TXR30 in multiparous cows is presented in Table 4. Variables were added to the predictive model by forward stepwise inclusion to maximize predictive accuracy. The variables included in the prediction equation for multiparous cows (Table 3) were similar to those included in the explanatory model (Table 4). Some differences between the effects of individual variables between the explanatory and predictive models were expected, because the models were derived differently and for different purposes.

Lactation group and calving abnormality were included as single variables in both models, and the direction of their effects was the same in both models (increasing parity increased both the odds of and the prediction of TXR30, and the presence of a calving abnormality increased both the odds of and the prediction of TXR30). These consistent findings reinforce the importance of effects of these 2 variables on TXR30.

Several interactions were observed involving prepartum locomotion score in the predictive model. Particularly noteworthy was the much higher log odds of TXR30 in lactation-3 cows with a prepartum locomotion score of 3 or 4 (estimate of 1.16 vs. estimates of -0.14 to 0.28 for the other interactions involving prepartum locomotion score and lactation group; Table 4), and the much higher predicted log odds of TXR30 for cows with a calving abnormality and a prepartum locomotion score of 3 or 4 (estimate of 1.74 vs. estimate 
Table 4. Predictive model for the log odds of TXR $30^{1}$ for multiparous cows in 4 commercial herds with predominantly Holstein cows ${ }^{2}$

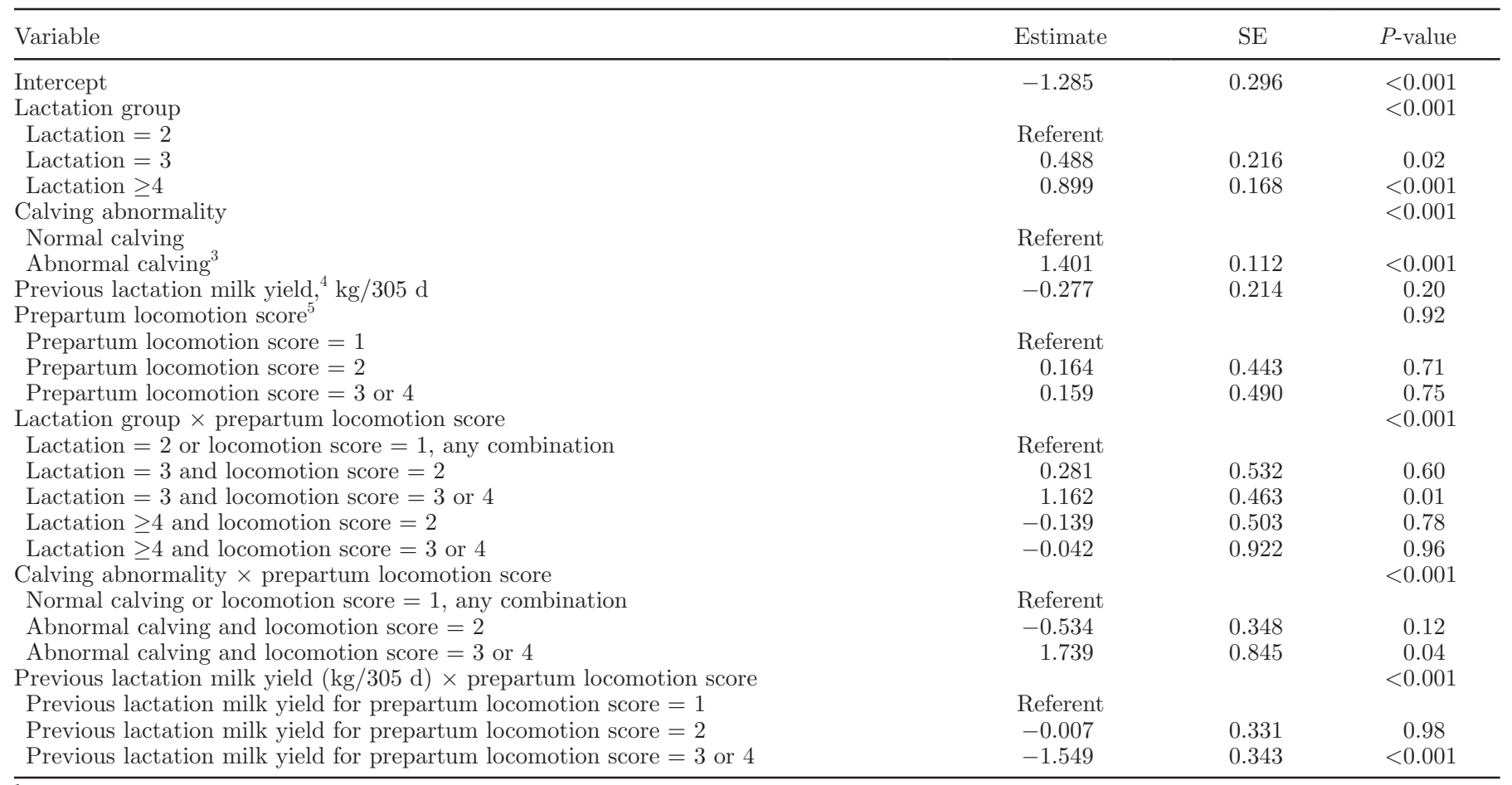

${ }^{1}$ Cows that, within $30 \mathrm{~d}$ of calving, received $\geq 1$ treatment for $\geq 1$ disease of interest, were removed from the herd, or both. Postpartum diseases of interest were milk fever, retained placenta, metritis, ketosis, displaced abomasum, lameness, and pneumonia.

${ }^{2}$ Herd was included in the model as a random effect. Predictors were added to the model by forward addition to maximize area under the receiver operating characteristic curve. The area under the curve for this model was 0.70 .

${ }^{3}$ One or more of the following: birth of twin calves, birth of a dead calf, or calving ease score $\geq 3$, using a scale of 1 to 5 .

${ }^{4}$ Mature-equivalent milk production ( $\mathrm{kg} / 305 \mathrm{~d}$ ), centered at $14,700 \mathrm{~kg}$ (the median value), and standardized to increments of $5,000 \mathrm{~kg}$. The range of the adjusted values was -1.79 to 1.49 .

${ }^{5}$ Locomotion scores were determined using a scale of 1 to 4 .

of -0.53 for cows with a calving abnormality and a prepartum locomotion score of 2; Table 4). Prepartum locomotion score was included as a single variable in the explanatory model, with a locomotion score 3 or 4 increasing the odds for TXR30. Considered together, these findings reinforce the negative effects of prepartum lameness on postpartum problems.

Previous lactation length was included in the explanatory model but not in the predictive model. The explanatory model offers the better biological explanation for the relationship between previous lactation length and postpartum problems; however, the lack of usefulness in predicting the risk for TXR30 suggests that the relationship could be weaker than for other variables that were included in both models.

Previous lactation milk production was included as an interaction term in both the explanatory and predictive models. In both models, the effect of higher previous lactation milk yield was beneficial; it either lowered the odds for TXR30 in cows with longer previous lactation length (explanatory model) or reduced the log odds of
TXR30 in cows with a prepartum locomotion score of 3 or 4 (predictive model).

The AUC for the ROC curve from the predictive model for multiparous cows was 0.70 (95\% CI: 0.66 to 0.74 ). The cutpoint in predicted probabilities that maximized the sum of sensitivity and specificity for the prediction of TXR30 was 0.40 . At this cutpoint, the prediction equation was $60 \%$ sensitive and $70 \%$ specific.

The AUC of the prediction equation for multiparous cows fell into the accurate or very accurate classification. This was similar to the ability of laboratory tests to predict postpartum events. For example, prepartum NEFA predicted a combination of diseases (metritis, RP, ketosis, or DA) with an AUC of $0.60,48 \%$ sensitivity, and $69 \%$ specificity (Ospina et al., 2010a). Other studies have evaluated prepartum NEFA for prediction of single diseases such as ketosis, DA, and metritis; reported sensitivities were between 25 and $76 \%$ (LeBlanc et al., 2005; Dubuc et al., 2010; Chapinal et al., 2011). Postpartum BHBA had $57 \%$ sensitivity in predicting whether cows would develop metritis, RP, ketosis, or 
DA (Ospina et al., 2010a), and BHBA had 57\% sensitivity for prediction of DA during the first week after calving (Chapinal et al., 2011). Prepartum BHBA is not as accurate and had only $22 \%$ sensitivity for prediction of DA (Chapinal et al., 2011). A direct comparison of the predictive abilities of laboratory tests with the results of the current study was not possible. Different potential risk factors and interactions were evaluated in the studies; the current study included a large number of potential risk factors and their interactions. It is not known whether the addition of laboratory test results would have improved predictive accuracy for TXR30. Also, different statistical methods were utilized by different studies; the current study used predictive modeling with the goal of maximizing predictive accuracy.

\section{Primiparous Cows}

Descriptive Statistics. The proportion of primiparous cows with TXR30 was $34.7 \%$ (189/544 cows). The proportions were $15.9,38.0,45.9$, and $28.2 \%$ for herds $\mathrm{A}, \mathrm{B}, \mathrm{C}$, and $\mathrm{D}$, respectively. The most frequently diagnosed disease was metritis $(22.6 \%$ of primiparous cows), followed by clinical ketosis (14.9\%), and RP $(4.2 \%)$. No MF was present and $1 \%$ or fewer of the primiparous cows were treated for pneumonia, lameness, or DA. Metritis incidence by herd ranged from 5.3 to $35.2 \%$, and ketosis incidence by herd ranged from 2.9 to $30.0 \%$. The overall removal rate by 30 DIM was $1.8 \%$ and ranged from 1.0 to $2.3 \%$ for the 4 study herds. Lameness was very infrequent in the primiparous cows (average incidence of $3.3 \%$, range of 0 to $5.6 \%$ for the 4 study herds).

Explanatory Model. The final explanatory model for TXR30 in the primiparous cows included calving abnormality, gestation length, herd, and the interaction between calving abnormality and gestation length (data not shown). Calving abnormality increased the odds of TXR30 (OR $=3.9 ; 95 \%$ CI: 2.3 to $6.8 ; P<$ 0.01 ) at median gestation length, which was $275 \mathrm{~d}$. It was particularly noteworthy that calving abnormality status changed the direction of the effect of gestation length on the odds of TXR30 (Figure 2). For primiparous cows without a calving abnormality, increasing gestation length increased the odds of TXR30 (OR = 1.4; $95 \%$ CI: 1.2 to 1.8 for each 1-SD increase, which was $6 \mathrm{~d} ; P<0.01)$. For primiparous cows with a calving abnormality, decreasing gestation length increased the odds of TXR30 ( OR $=0.6 ; 95 \%$ CI: 0.4 to 0.9 for each 6 -d increase in gestation length; $P<0.01$ ). The 2 groups of primiparous cows with the highest odds of TXR30 were those with short gestation length and a calving abnormality or (to a lesser extent) those with long gestation length and no calving abnormality.
This result was not intuitive but is supported by the findings of Bleul (2011), who reported increased risk of stillbirths in primiparous cows at both extremes of gestation length (260 to $272 \mathrm{~d}$ and 302 to $330 \mathrm{~d}$ ) but did not consider interaction terms and evaluated outcomes pertaining only to the calves born in the study (not their dams).

Herd was included in the explanatory model for TXR30 in primiparous cows as it was for the multiparous cohort. This finding again illustrates the importance of general herd management in determining the odds of postpartum problems.

Predictive Model. Only 2 variables were included in the final prediction equation for TXR30 in primiparous cows: age at calving and calving abnormality (data not shown). The AUC for this prediction was 0.66 (95\% CI: 0.62 to 0.71 ), which was similar to the value for the multiparous cow predictive model. However, the sensitivity at the cutpoint with the best combination with specificity was only $35 \%$. The lack of information from the previous lactation for primiparous cows likely contributed to the small number of predictors in the final model for primiparous cows and also to its low sensitivity.

Calving abnormality was included in both explanatory and predictive models for TXR30 in primiparous cows. However, the explanatory model also included gestation length, which was not in the prediction equation, and the prediction equation included age at calving, which was not in the explanatory model. Disparities between the predictive and explanatory models illustrate the challenge of predicting TXR30 in primiparous cows.

\section{Comparison of Models for the Multiparous Versus Primiparous Cohorts}

Different variables were required to explain TXR30 for primiparous and multiparous cows. The only variables included in both the primiparous and multiparous explanatory models for TXR30 were herd and calving abnormality. Two variables not applicable to primiparous cows (previous lactation milk yield and lactation length) were included in the final explanatory model for multiparous cows. Additionally, lameness was very infrequent in primiparous cows and was not included in the final explanatory model, as it was for the multiparous cows.

\section{CONCLUSIONS}

Explanatory model and predictive models for postpartum problems (expressed as the combined outcome for cows that within 30 DIM were treated for 


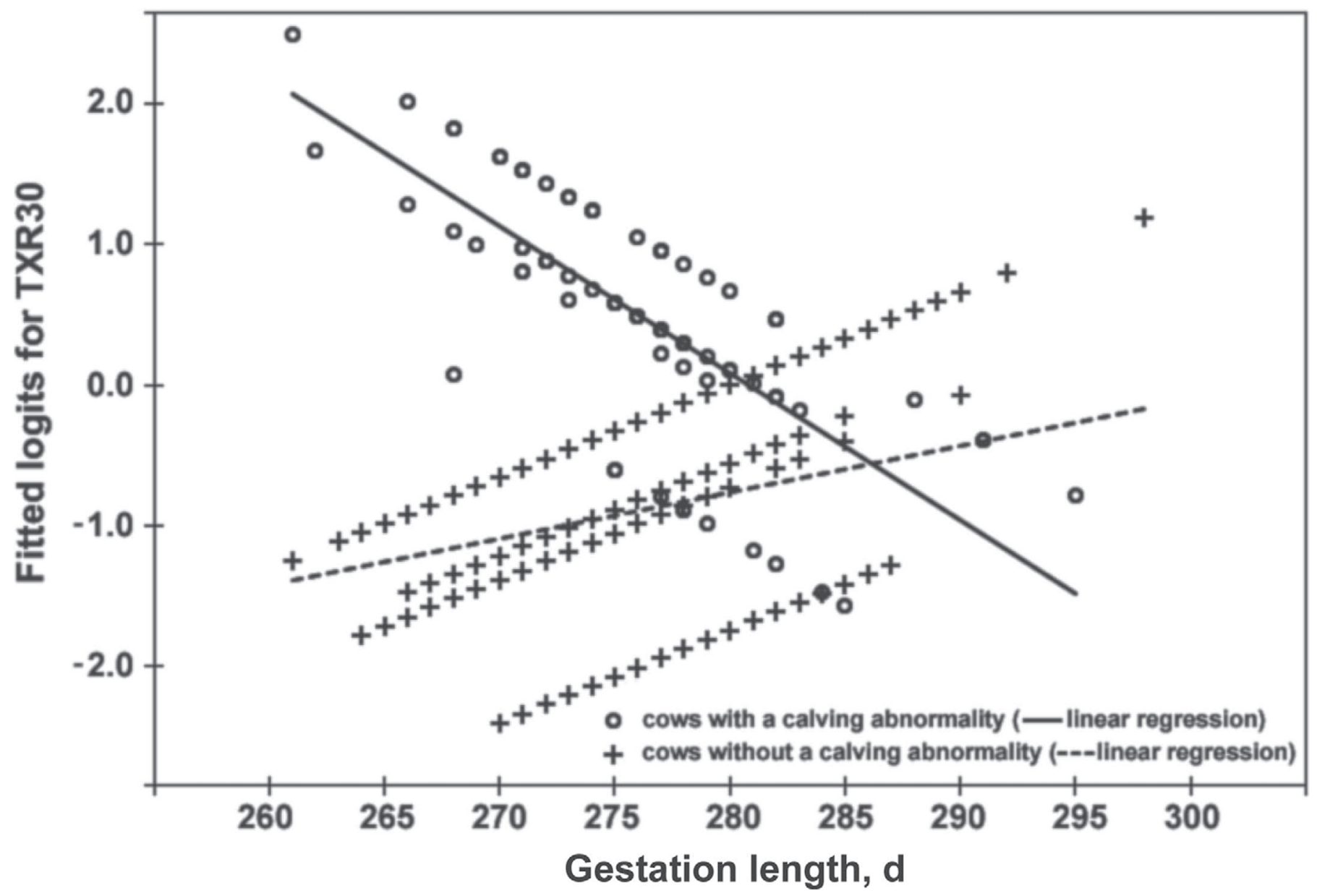

Figure 2. Graphical representation of the interaction between gestation length and calving abnormality for a model explaining postpartum disease treatment, herd removal, or both by 30 DIM (TXR30) for primiparous cows in 4 commercial Holstein herds. The interaction between gestation length and calving abnormality was included $(P<0.001)$ in the final logistic regression model. Results are plotted as the fitted logits from the final logistic regression model.

disease, removed from the herd, or both) were derived separately for multiparous and primiparous cohorts of cows. Calving abnormality (twins, stillbirth, or dystocia) increased the odds of TXR30 in both cohorts. Combinations of risk factors also resulted in very high odds of TXR30, such as multiparous cows with calving abnormality plus longer previous lactation length, and primiparous cows with shorter gestation length. Dairy producers could benefit from the knowledge that these specific combinations of risk factors result in very high odds of postpartum problems. Multiparous cows that were lame (locomotion score $=3$ or 4 ) had greater odds of TXR30; however, lameness was infrequent in primiparous cows and did not affect the odds of TXR30. Prepartum locomotion score can be used both as a monitor for herd lameness and as an explanatory variable for postpartum problems. Higher previous lactation milk production was protective against postpartum problems for multiparous cows with longer previous lactation lengths. Dairy producers could direct more attention to postpartum cows that gave less milk in their previous lactation. Prediction equations from the predictive models had moderate accuracy for multiparous cows but poor accuracy for primiparous cows. Predictions from the multiparous model had similar AUC, sensitivity, and specificity compared with previously reported models that evaluated a variety of different blood measures to predict different postpartum outcomes.

\section{ACKNOWLEDGMENTS}

This study was funded in part by Becas Chile (Ministry of Education, Santiago, Chile), ABS Latin America (Santiago, Chile), USDA-NRI (Washington, DC), and Boehringer Ingelheim Vetmedica Inc. (St. Joseph, MO). The authors thank Lindley Reilly, Eric Rooker, Angela Niles, Nick Keuler, Arturo Gomez, Sonia A. Gomez, 
Tom Bennett, Chris Eisele, Tyler Franks, Catherine Bargren, Diego Calderon, Loïc Commun, and Marsha Bush (all from University of Wisconsin, Madison), and Judith Alishauskas, Stephanie Brittin, Emily Bold, Mark Fagan, and Caitlin Jeffrey (all from Cornell University, Ithaca, NY) for their invaluable assistance with data collection and analysis. We thank the owners and employees of the collaborating dairies for granting us access to their facilities, cows, and herd records.

\section{REFERENCES}

AgSource.2014. Holstein benchmarks by herdsize; revisedJanuary1,2014. Accessed Apr. 14, 2014. http://documents.crinet.com/AgSourceCooperative-Services/DHI/Benchmark-HolsteinsBySize-over-250_ 2014.pdf.

Bicalho, R. C., K. N. Galvao, L. D. Warnick, and C. L. Guard. 2008. Stillbirth parturition reduces milk production in Holstein cows. Prev. Vet. Med. 84:112-120.

Bleul, U. 2011. Risk factors and rates of perinatal and postnatal mortality in cattle in Switzerland. Livest. Sci. 135:257-264.

Burton, J. L., S. A. Madsen, L. C. Chang, P. S. Weber, K. R. Buckham, R. van Dorp, M. C. Hickey, and B. Earley. 2005. Gene expression signatures in neutrophils exposed to glucocorticoids: A new paradigm to help explain "neutrophil dysfunction" in parturient dairy cows. Vet. Immunol. Immunopathol. 105:197-219.

Calderon, D. F., and N. B. Cook. 2011. The effect of lameness on the resting behavior and metabolic status of dairy cattle during the transition period in a freestall-housed dairy herd. J. Dairy Sci. 94:2883-2894.

Chapinal, N., M. Carson, T. F. Duffield, M. Capel, S. Godden, M. Overton, J. E. Santos, and S. J. LeBlanc. 2011. The association of serum metabolites with clinical disease during the transition period. J. Dairy Sci. 94:4897-4903.

Cheong, S. H., D. V. Nydam, K. N. Galvão, B. M. Crosier, and R. O Gilbert. 2011. Cow-level and herd-level risk factors for subclinical endometritis in lactating Holstein cows. J. Dairy Sci. 94:762-770.

Cook, N. B. 2003. Prevalence of lameness among dairy cattle in Wisconsin as a function of housing type and stall surface. J. Am. Vet. Med. Assoc. 223:1324-1328.

De Vries, A., J. D. Olson, and P. J. Pinedo. 2010. Reproductive risk factors for culling and productive life in large dairy herds in the eastern United States between 2001 and 2006. J. Dairy Sci. 93:613-623.

Dechow, C. D., and R. C. Goodling. 2008. Mortality, culling by sixty days in milk, and production profiles in high- and low-survival Pennsylvania herds. J. Dairy Sci. 91:4630-4639.

DeLong, E. R., D. M. DeLong, and D. L. Clarke-Pearson. 1988. Comparing the areas under two or more correlated receiver operating characteristic curves: A nonparametric approach. Biometrics 44:837-845.

Dubuc, J., T. F. Duffield, K. E. Leslie, J. S. Walton, and S. J. LeBlanc. 2010. Risk factors for postpartum uterine diseases in dairy cows. J. Dairy Sci. 93:5764-5771.

Espejo, L. A., and M. I. Endres. 2007. Herd-level risk factors for lameness in high-producing Holstein cows housed in freestall barns. J. Dairy Sci. 90:306-314.

Ferguson, J. D., D. T. Galligan, and N. Thomsen. 1994. Principal descriptors of body condition score in Holstein cows. J. Dairy Sci. 77:2695-2703.

Fleischer, P., M. Metzner, M. Beyerbach, M. Hoedemaker, and W. Klee. 2001. The relationship between milk yield and the incidence of some diseases in dairy cows. J. Dairy Sci. 84:2025-2035.

Gomez, A., and N. B. Cook. 2010. Time budgets of lactating dairy cattle in commercial freestall herds. J. Dairy Sci. 93:5772-5781.

Greiner, M., D. Pfeiffer, and R. D. Smith. 2000. Principles and practical application of the receiver-operating characteristic analysis for diagnostic tests. Prev. Vet. Med. 45:23-41.
Grummer, R. R., D. G. Mashek, and A. Hayirli. 2004. Dry matter intake and energy balance in the transition period. Vet. Clin. North Am. Food Anim. Pract. 20:447-470.

Guterbock, W. M. 2004. Diagnosis and treatment programs for fresh cows. Vet. Clin. North Am. Food Anim. Pract. 20:605-626.

Hammon, D. S., I. M. Evjen, T. R. Dhiman, J. P. Goff, and J. L. Walters. 2006. Neutrophil function and energy status in Holstein cows with uterine health disorders. Vet. Immunol. Immunopathol. 113:21-29.

Hoedemaker, M., D. Prange, and Y. Gundelach. 2009. Body condition change ante- and postpartum, health and reproductive performance in German Holstein cows. Reprod. Domest. Anim. 44:167-173.

Huzzey, J. M., D. V. Nydam, R. J. Grant, and T. R. Overton. 2011. Associations of prepartum plasma cortisol, haptoglobin, fecal cortisol metabolites, and nonesterified fatty acids with postpartum health status in Holstein dairy cows. J. Dairy Sci. 94:5878-5889.

Ingvartsen, K. L. 2006. Feeding- and management-related diseases in the transition cow: Physiological adaptations around calving and strategies to reduce feeding-related diseases. Anim. Feed Sci. Technol. 126:175-213.

Ingvartsen, K. L., R. J. Dewhurst, and N. C. Friggens. 2003. On the relationship between lactational performance and health: Is it yield or metabolic imbalance that cause production diseases in dairy cattle? A position paper. Livest. Prod. Sci. 83:277-308.

Landis, J. R., and G. G. Koch. 1977. The measurement of observer agreement for categorical data. Biometrics 33:159-174.

LeBlanc, S. 2010. Monitoring metabolic health of dairy cattle in the transition period. J. Reprod. Dev. 56(Suppl.):S29-S35.

LeBlanc, S. J., K. E. Leslie, and T. F. Duffield. 2005. Metabolic predictors of displaced abomasum in dairy cattle. J. Dairy Sci. 88:159-170.

LeBlanc, S. J., K. D. Lissemore, D. F. Kelton, T. F. Duffield, and K. E. Leslie. 2006. Major advances in disease prevention in dairy cattle. J. Dairy Sci. 89:1267-1279.

Machado, V. S., L. S. Caixeta, and R. C. Bicalho. 2011. Use of data collected at cessation of lactation to predict incidence of sole ulcers and white line disease during the subsequent lactation in dairy cows. Am. J. Vet. Res. 72:1338-1343.

Machado, V. S., L. S. Caixeta, J. A. A. McArt, and R. C. Bicalho. 2010. The effect of claw horn disruption lesions and body condition score at dry-off on survivability, reproductive performance, and milk production in the subsequent lactation. J. Dairy Sci. 93:4071-4078.

Markusfeld, O., N. Galon, and E. Ezra. 1997. Body condition score, health, yield and fertility in dairy cows. Vet. Rec. 141:67-72.

McArt, J. A., D. V. Nydam, P. A. Ospina, and G. R. Oetzel. 2011. A field trial on the effect of propylene glycol on milk yield and resolution of ketosis in fresh cows diagnosed with subclinical ketosis. J. Dairy Sci. 94:6011-6020.

Nordlund, K. V., and N. B. Cook. 2004. Using herd records to monitor transition cow survival, productivity, and health. Vet. Clin. North Am. Food Anim. Pract. 20:627-649.

Nordlund, K. V., N. B. Cook, and G. R. Oetzel. 2004. Investigation strategies for laminitis problem herds. J. Dairy Sci. 87(E. Suppl.):E27-E35.

Oetzel, G. R., and B. E. Miller. 2012. Effect of oral calcium bolus supplementation on early-lactation health and milk yield in commercial dairy herds. J. Dairy Sci. 95:7051-7065.

Ospina, P. A., D. V. Nydam, T. Stokol, and T. R. Overton. 2010a. Evaluation of nonesterified fatty acids and beta-hydroxybutyrate in transition dairy cattle in the northeastern United States: Critical thresholds for prediction of clinical diseases. J. Dairy Sci. 93:546-554.

Ospina, P. A., D. V. Nydam, T. Stokol, and T. R. Overton. 2010b. Evaluation of nonesterified fatty acids and beta-hydroxybutyrate concentrations with early lactation reproductive performance and milk production in transition dairy cattle in the northeastern United States. J. Dairy Sci. 93:1596-1603.

Roberts, T., N. Chapinal, S. J. Leblanc, D. F. Kelton, J. Dubuc, and T. F. Duffield. 2012. Metabolic parameters in transition cows as 
indicators for early-lactation culling risk. J. Dairy Sci. 95:30573063.

Ruegg, P. L., and R. L. Milton. 1995. Body condition scores of Holstein cows on Prince Edward Island, Canada: Relationships with yield, reproductive performance, and disease. J. Dairy Sci. 78:552-564.

Seifi, H. A., S. J. Leblanc, K. E. Leslie, and T. F. Duffield. 2011. Metabolic predictors of post-partum disease and culling risk in dairy cattle. Vet. J. 188:216-220.

Shmueli, G. 2011. To explain or predict? Stat. Sci. 25:289-310.

Swets, J. A. 1988. Measuring the accuracy of diagnostic systems. Science 240:1285-1293.
USDA. 2007. Dairy 2007, Part I: Reference of Dairy Cattle Health and Management Practices in the United States, 2007. USDA-APHISVS, CEAH, Fort Collins, CO.

Vittinghoff, E., D. V. Glidden, S. C. Shiboski, and C. E. McCulloch. 2005. Regression Methods in Biostatistics: Linear, Logistic, Survival, and Repeated Measures Models. Springer, New York, NY.

von Keyserlingk, M. A. G., A. Barrientos, K. Ito, E. Galo, and D. M. Weary. 2012. Benchmarking cow comfort on North American freestall dairies: Lameness, leg injuries, lying time, facility design, and management for high-producing Holstein dairy cows. J. Dairy Sci. 95:7399-7408 